\title{
Intermittent maternal hypoxia has an influence on regional expression of endothelial nitric oxide synthase in fetal arteries of rabbits
}

\author{
You-fang Chen ${ }^{1}$, Zhen-hua Wang ${ }^{2,3}$, Zhi-kui Chen ${ }^{4}$, Guo-rong Lv $^{5}$ and Markus Ferrari ${ }^{3}$
}

BACKGROUND: Maternal hypoxia induces sustained fetal adaptations associated with changes in gene expression. We hypothesized that intermittent maternal hypoxia has an influence on regional expression of endothelial nitric oxide synthase (eNOS) in fetal arteries of New Zealand White rabbits.

METHODS: Timed-pregnant New Zealand White rabbits (term $=30 \pm 1 \mathrm{~d}$ ) were randomly assigned to a normoxic control group $(n=5)$ or a hypoxia group $\left(12 \% \mathrm{O}_{2^{\prime}} n=5\right)$ during days 10-29 of pregnancy. At the end of pregnancy (29 $d$ gestation), blood samples were collected from mothers and fetuses. Carotid and femoral arteries of fetuses were extracted for eNOS mRNA and protein concentration and analysis of total NOS activities.

RESULTS: Our data demonstrate that chronic intermittent maternal hypoxia significantly increased eNOS mRNA and protein concentrations and total NOS activities in carotid artery segments but decreased eNOS mRNA and protein concentrations and total NOS activities in femoral artery segments in the same fetuses. Vascular endothelial cells, but not smooth muscle cells, of fetal rabbits exhibited positive immunostaining for the eNOS protein.

CONCLUSION: These observations suggest that chronic hypoxia can regulate regional expression of eNOS as an adaptive response to hypoxic stress in fetal arteries.

$\mathrm{H}$ ypoxia is the most important and clinically relevant stress to which the fetus is exposed (1-3). Many conditions in pregnant women, including exposure to high altitude; smoking; exposure to environmental pollution with carbon monoxide; anemia; placental insufficiency; cord compression; preeclampsia; diseases of the heart, lung, and kidney; or hemoglobinopathy can cause hypoxemic stress to the fetus (1). The compensatory responses of the fetus to hypoxia are variable and depend on the duration and severity of hypoxic exposure. Cardiovascular responses to acute hypoxic stress include neuroreflex and endocrine responses, which result in decreases in fetal heart rate, increases in mean arterial pressure, and fetal cardiac output redistribution (4). Prolonged exposure to hypoxia induces sustained fetal adaptations associated with changes in gene expression, fetal growth restriction, and organspecific growth $(5,6)$. It has been clearly demonstrated that one of the important fetal adaptations to either acute or sustained hypoxia is a redistribution of fetal cardiac output to ensure a preferential supply of nutrients to the brain and the heart and maintain their growth at the expense of the periphery $(7,8)$. The redistribution of fetal cardiac output during hypoxia may partially depend on the balance between vasomotor influences of circulating catecholamines (9) and those of endotheliumderived relaxing factors such as nitric oxide (NO) (10).

$\mathrm{NO}$ is an important physiologic modulator of blood flow and is derived from three isoforms of NO synthase (NOS): endothelial NOS (eNOS, NOS-3), inducible NOS (NOS-2), and neuronal NOS (NOS-1) (11). Endothelial cell-generated NO accounts for a large part of the labile vasodilator termed "endothelium-derived relaxing factor" (12), and it plays an important role in modulating relaxation of the underlying vascular smooth muscle via the cyclic guanosine monophosphate synthesis pathway (eNOS-NO-cyclic guanosine monophosphate pathway) $(13,14)$. Williams et al. (15) reported that NO is the primary vasodilator molecule released from the endothelium of both mature and immature ovine carotid arteries. Thompson et al. $(16,17)$ demonstrated the important role of NO in enhanced fetal carotid artery vasodilation in response to prolonged maternal hypoxia; subsequently, they reported that chronic maternal hypoxia in a $12 \% \mathrm{O}_{2}$ atmosphere $(14 \mathrm{~d})$ increased eNOS protein levels in fetal carotid arteries by fourfold (18).

To determine whether a reduced oxygen supply in utero has a differential effect on eNOS expression among different vascular tissues within the same fetus, we investigated the effects of chronic intermittent maternal hypoxia on eNOS expression in two distinct arteries in fetal rabbits: the carotid artery, which supplies blood to the brain, and the femoral artery, which supplies the periphery. Quantification of the changes in eNOS expression in the fetal arteries is an important step in understanding how chronic hypoxia can regulate NO production as

'Department of Clinical Medicine, Quanzhou Medical College, Quanzhou, China; ${ }^{2}$ Department of Cardiology, Second Affiliated Hospital of Fujian Medical University, Quanzhou, China; ${ }^{3}$ Division of Cardiology, Department of Internal Medicine I, Friedrich-Schiller-University Jena, Jena, Germany; ${ }^{4}$ Department of Ultrasound, Affiliated Union Hospital of Fujian Medical University, Fuzhou, China; ${ }^{5}$ Department of Ultrasound, Second Affiliated Hospital of Fujian Medical University, Quanzhou, China. Correspondence: Guo-rong Lv (lgr_feus@sina.com) 
a

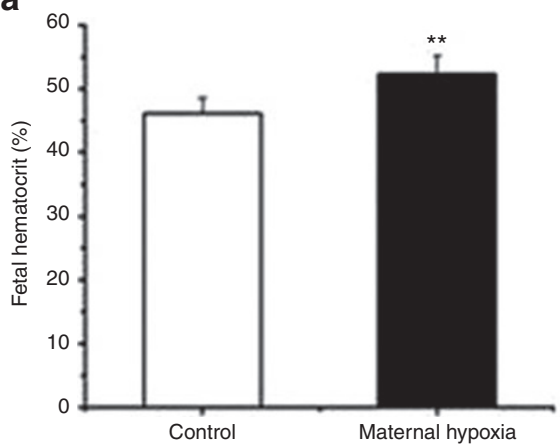

b

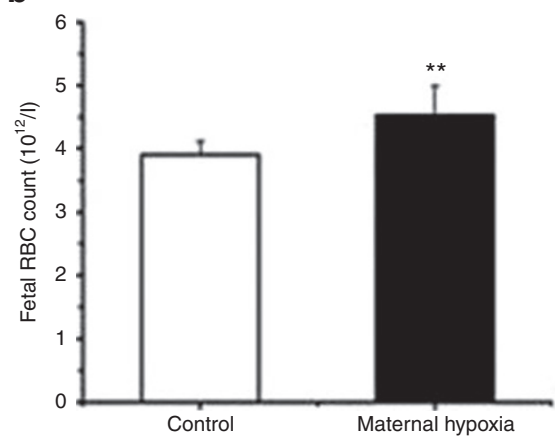

C

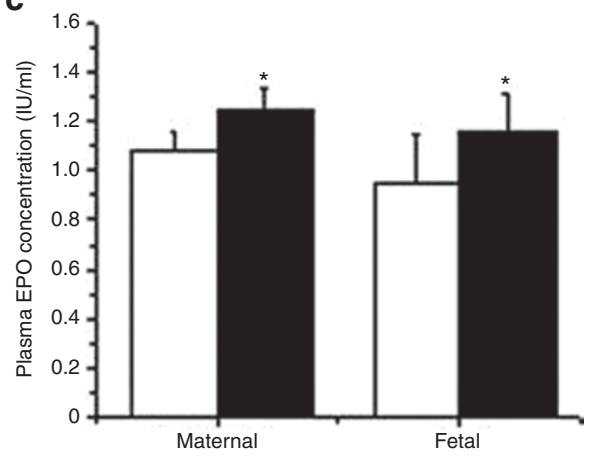

Figure 1. Effect of chronic intermittent maternal hypoxia on (a) fetal hematocrit, (b) red blood cell (RBC) count, and (c) maternal and fetal erythropoietin (EPO) concentration. All data are expressed as means \pm SD for control (white bars; maternal $n=5$ and fetal $n=10$ ) and maternal hypoxia (black bars; maternal $n=5$ and fetal $n=10$ ) animals. ${ }^{*} P<0.05 ;{ }^{* *} P<0.01$, as compared with control.

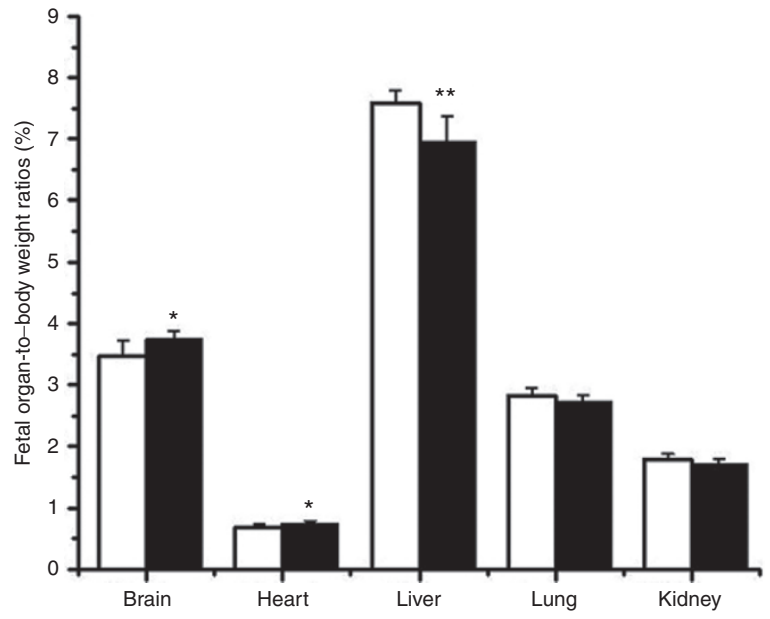

Figure 2. Organ weight-to-body weight ratios of brain, heart, lung, liver, and kidneys in control (white bars, $n=10$ ) and maternal hypoxia (black bars, $n=10$ ) fetuses. ${ }^{*} P<0.05$; ${ }^{* *} P<0.01$, as compared with control.

an adaptive response to hypoxic stress. This is the first study to identify a differential response of eNOS expression in distinct arteries of fetuses in response to chronic hypoxia.

\section{RESULTS}

\section{Maternal and Fetal Blood Sample Values}

We measured erythropoietin (EPO) as an index of maternal hypoxemia and measured hematocrit, red blood cell (RBC) count, and EPO as indexes of fetal hypoxemia (Figure 1). Chronic maternal hypoxia significantly increased maternal EPO $(P<0.05)$ and fetal hematocrit $(P<0.01), \mathrm{RBC}$ count $(P<$ $0.01)$, and EPO $(P<0.05)$ values as compared with the respective control. These results show that chronic maternal hypoxia induced significant maternal and fetal hypoxemia.

\section{Fetal Weights and Organ-to-Body Weight Ratios}

The birth weights of maternal hypoxia fetuses were significantly reduced as compared with those of control fetuses $(57.91 \pm 4.21$ vs. $62.04 \pm 3.27 \mathrm{~g} ; P<0.05)$. In addition, the brainto-body weight ratio and heart-to-body weight ratio were significantly $(P<0.05)$ higher, and the liver-to-body weight ratio was significantly lower $(P<0.01)$ in maternal hypoxia fetuses as compared with controls. But there were no obvious differences in mean weight ratios of the lung and kidney (Figure 2). These results indicate that maternal exposure to hypoxia resulted in disproportionate intrauterine growth restriction of fetal organs.

\section{eNOS Protein}

The effect of hypoxia on eNOS protein expression in fetal carotid (Figure 3a) and femoral arteries (Figure 3c) was quantified by western blot analysis. eNOS protein was identified by single $140-\mathrm{kDa}$ bands in both fetal carotid and femoral artery samples. Carotid (Figure 3b) and femoral (Figure 3d) artery $\beta$-actin $(42 \mathrm{kDa})$ bands showed equal loading of the samples. eNOS protein bands were quantified by densitometry and the average optical density values plotted in the corresponding figures.

eNOS protein was constitutively expressed in both the fetal carotid and femoral arteries of the control and maternal hypoxia groups. The results are shown as a ratio of eNOS to $\beta$-actin densitometry (Figure 3e), which illustrates a significant increase $(P<0.05)$ in eNOS protein in carotid arteries from maternal hypoxia fetuses as compared with control fetuses. By contrast, eNOS protein levels in femoral arteries from maternal hypoxia fetuses were significantly lower $(P<0.05)$ than those of control fetuses.

\section{Total NOS Activities}

Figure 4 illustrates the activities of total NOS in fetal artery segments. Similar to eNOS protein levels, maternal hypoxia significantly increased total NOS activities of fetal carotid artery segments $(P<0.05)$ and decreased the enzyme activity in fetal femoral artery segments $(P<0.05)$.

\section{eNOS mRNA}

eNOS mRNA levels in fetal artery segments were quantified using real-time reverse-transcriptase PCR and expressed as $2-\Delta \Delta$ cycle threshold $\left(C_{t}\right)$ values. Figure 5 illustrates the average eNOS mRNA of isolated fetal carotid and femoral artery segments from the same fetuses. Maternal hypoxia 

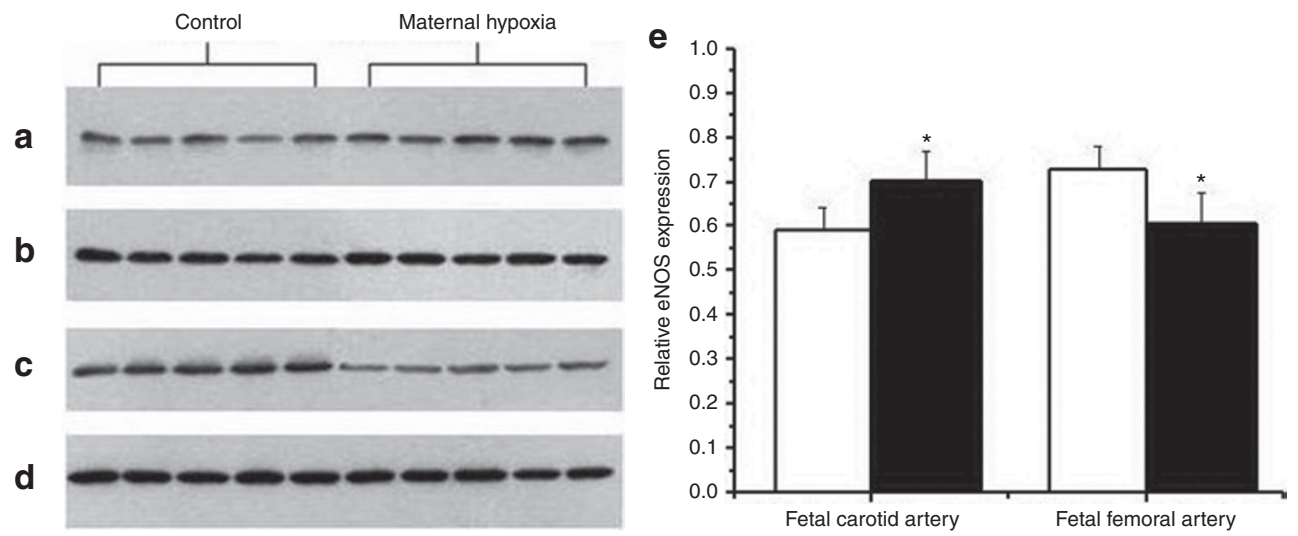

Figure 3. Endothelial nitric oxide synthase (eNOS) immunoblots. (a) Carotid and (c) femoral artery eNOS immunoblots from control (white bars, $n=5$ ) and maternal hypoxia (black bars, $n=5$ ) fetuses. Each lane represents samples pooled from two different fetuses from the same litter. (b) Carotid and (d) femoral artery $\beta$-actin bands show an equal loading of samples. (e) The results are shown as a ratio of eNOS to $\beta$-actin densitometry. ${ }^{*} P<0.05$, as compared with control.

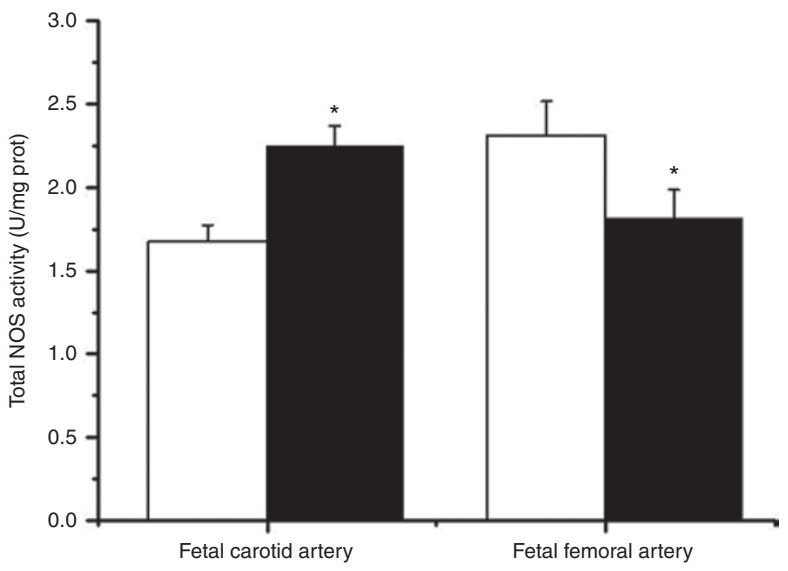

Figure 4. Total nitric oxide synthase (NOS) activities of isolated fetal carotid and femoral artery segments of control (white bars, $n=5$ ) and maternal hypoxia (black bars, $n=5$ ) fetuses. ${ }^{*} P<0.05$, as compared with control. prot, protein.

significantly increased eNOS mRNA levels of fetal right common carotid artery segments $(P<0.01)$ and decreased mRNA values of fetal right femoral artery segments $(P<$ 0.05 ). This identifies a distinct effect of hypoxia on eNOS mRNA expression that differs within fetal arteries and is regionally specific.

\section{Immunohistochemical Analysis}

Immunohistochemistry revealed eNOS to be localized only within endothelial cells in fetal artery preparations. Immunoreactivity to eNOS in carotid arteries from maternal hypoxia fetuses (Figure 6c) showed a significant increase in staining intensity vs. controls (Figure 6a). By contrast, immunoreactivity to eNOS in femoral arteries from maternal hypoxia fetuses (Figure $6 \mathrm{~g}$ ) showed a significant decrease in staining intensity vs. controls (Figure 6e). A significant difference was found in the expression of eNOS with average optical density of positive cells in the fetal carotid arteries $(P<0.05)$ as well as femoral arteries $(P<0.01)$ between the maternal hypoxia and control groups (Figure 7).

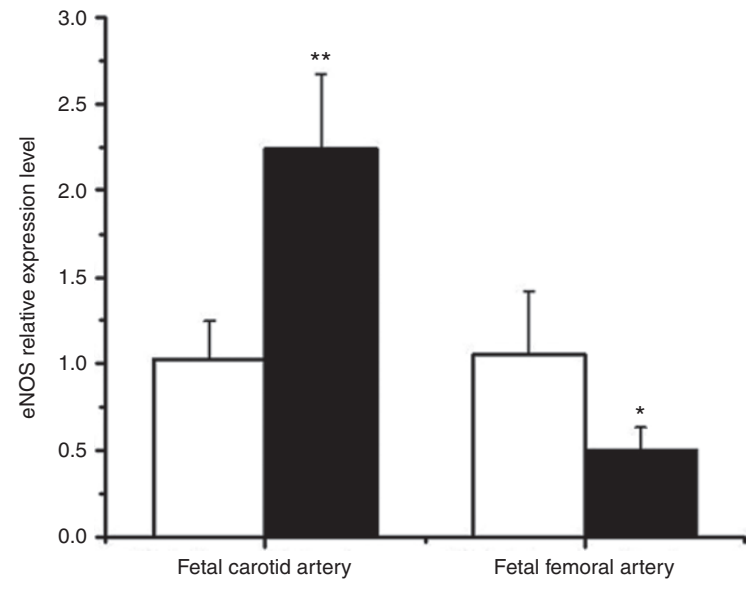

Figure 5. Endothelial nitric oxide synthase (eNOS) mRNA levels of isolated fetal carotid and femoral artery segments of control (white bars, $n=5$ ) and maternal hypoxia (black bars, $n=5$ ) fetuses. mRNA expression levels are measured as the $2-\Delta \Delta C_{t}$ values and compared between control and maternal hypoxia animals. ${ }^{*} P<0.05$; ${ }^{* *} P<0.01$, as compared with control.

\section{DISCUSSION}

The regulation of arterial blood flow is crucial for growth and survival of the fetus during hypoxia. However, the adaptive mechanisms of the fetal vasculature to chronic hypoxia during pregnancy are unclear, and endothelium-derived NO may play an important role in enhanced fetal artery vasodilation in response to chronic hypoxia (16-18). To our knowledge, the current study is the first to determine the impact of chronic maternal hypoxia on eNOS gene expression in distinct arteries in the same fetus.

To determine whether $19 \mathrm{~d}$ of maternal intermittent hypoxia with $12 \% \mathrm{O}_{2}$ induces fetal hypoxemia, we measured $\mathrm{EPO}$ as an index of maternal hypoxemia and measured hematocrit, RBC count, and EPO as indexes of fetal hypoxemia. Our data demonstrated that chronic intermittent maternal hypoxia significantly increased maternal EPO $(P<0.05)$ and fetal hematocrit $(P<0.01)$, RBC count $(P<0.01)$, and EPO $(P<0.05)$ values as compared with controls, suggesting that chronic intermittent maternal hypoxia induced significant maternal and fetal hypoxemia, which is consistent with previous results $(17,18)$. 

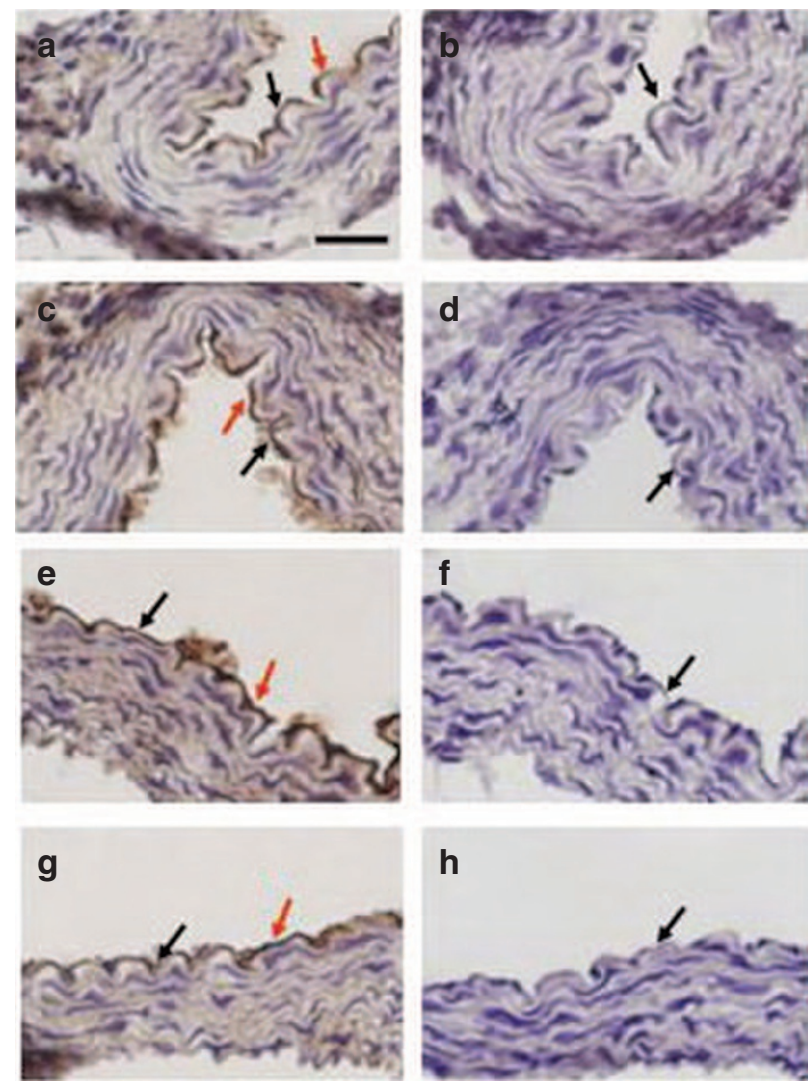

h

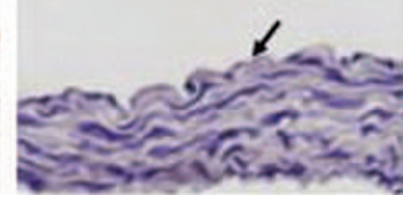

Figure 6. Immunohistochemistry for endothelial nitric oxide synthase (eNOS) localization in fetal carotid and femoral arteries. In these primary microphotographs, dark brown staining of the endothelial monolayer along the interior luminal surface of fetal carotid and femoral arteries indicates eNOS-positive cells (red arrows). Positive staining for eNOS in fetal carotid arteries of (a) control and (c) maternal hypoxia animals. (b,d) Corresponding negative controls. Positive staining for eNOS in fetal femoral arteries of (e) control and (g) maternal hypoxia animals. (f,h) Corresponding negative controls. Bar $=50 \mu \mathrm{m}$ and applies to all panels. Black arrows point to the endothelium.

Our data showed that a reduction in maternal oxygen supply during days 10-29 of gestation resulted in reduced fetus size and perturbations of fetal organ weight and proportion, the latter suggesting fetal organ-specific growth. Previous studies showed that chronic maternal hypoxia of different severity and at different gestational ages in pregnant rats reduces fetal $(19)$ or neonatal $(20,21)$ body weight and alters fetal organ growth. Conservation of brain and heart growth and reduced liver growth in fetuses after maternal hypoxia suggest that chronic maternal hypoxia caused changes in peripheral and/ or central artery resistance that redistributed cardiac output. The vascular resistance may depend on the balance between vasomotor influences of circulating catecholamines $(9,10)$ and of endothelium-derived relaxing factors such as $\mathrm{NO}(10)$. Our study illustrates a differential effect of chronic intermittent maternal hypoxia on eNOS protein and mRNA expression in the common carotid and femoral artery segments of fetal rabbits. With intermittent maternal hypoxia, the fetal common carotid artery showed higher levels of eNOS mRNA, protein, and total NOS activities than did control tissue. The mRNA,

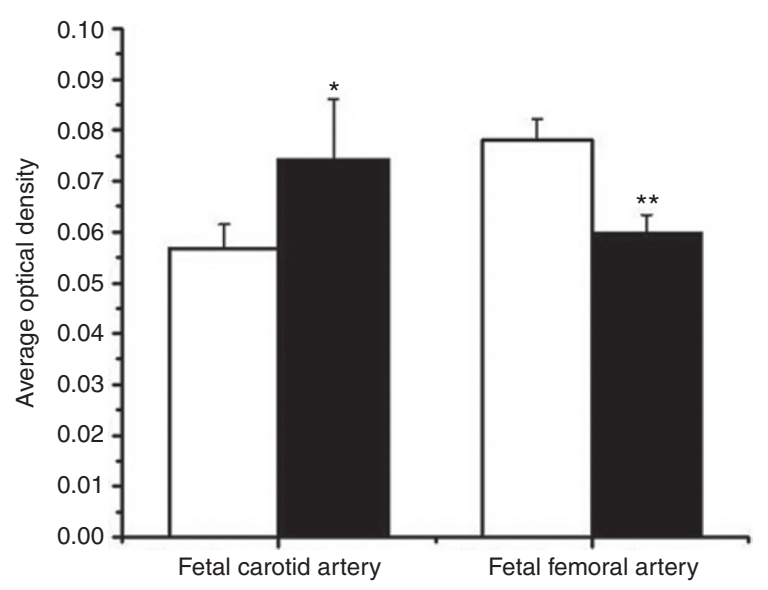

Figure 7. Average optical density of endothelial nitric oxide synthase of fetal carotid and femoral arteries. ${ }^{*} P<0.05$; ${ }^{* *} P<0.01$, maternal hypoxia (black bars) as compared with control (white bars).

protein, and enzyme expressions in the femoral artery were lower after hypoxia than those found in control tissues. Our study demonstrates that eNOS is immunolocalized in the vascular endothelial cells but not in vascular smooth muscle cells, which is similar to previous results (22). The current study demonstrates that chronic intermittent maternal hypoxia induces an altered eNOS gene expression in common carotid and femoral artery segments of fetal rabbits, and that regional selectivity of the effects on chronic hypoxia may contribute to the redistribution of fetal cardiac output during hypoxia.

Hypoxia alters the endothelial properties of fetal pulmonary (23), fetal carotid $(16,17)$, cerebral $(24)$, and femoral arteries $(10,25,26)$. The effect of chronic hypoxia on fetal tissue eNOS gene expression is variable among different cell types. For example, chronic maternal hypoxia with $12 \% \mathrm{O}_{2}$ for $14 \mathrm{~d}$ increases eNOS protein levels in fetal guinea pig carotid artery segments, whereas there is no effect on eNOS in fetal hearts of the same animals (18). The same group also reported that chronic maternal hypoxia of $10.5 \% \mathrm{O}_{2}$ for $14 \mathrm{~d}$ upregulates eNOS mRNA and protein expression in coronary arteries from fetal guinea pigs, although it downregulates mRNA and protein expression in cardiac tissue of the same animals (27). Chronic exposure to hypoxia can reduce sensitivity to acetylcholine by lowering NO release in the chicken embryo femoral artery (25), which is consistent with our results that chronic maternal hypoxia decreased the expression of eNOS activities in fetal femoral artery segments.

The mechanisms underlying this regional variability in eNOS protein expression in response to chronic hypoxia in vivo are not currently clear and may be related to hypoxia per se or changes of arterial shear stress. It is not unlikely that hypoxia per se may have different regulatory effects on eNOS protein and mRNA in different vascular beds. However, studies $(12,28,29)$ in cultured endothelial cells have yielded conflicting results of the effects of 24-h hypoxia on eNOS protein and mRNA expression. Arterial shear stress may also influence the expression of the eNOS gene. Because a shear stressresponsive element has been characterized in the promoter 
sequence of the human and bovine eNOS gene (30-32), the changes in blood flow occurring during fetal hypoxemia may alter arterial shear stress (26), which in turn can modulate the expression and activity of eNOS (33). One of the well-studied signaling pathways activated during endothelial response to shear stress is the cascade consisting of G-protein $\rightarrow$ phospholipase $\mathrm{C} / \mathrm{Ca}^{2+} \rightarrow$ protein kinase $\mathrm{C} \rightarrow \mathrm{c}$-fos/c-jun $\rightarrow$ activator protein 1 site-dependent transcription; this pathway is operative in the elevation of eNOS expression by shear stress. Therefore, in the current study, the hypoxia-induced increase in carotid artery eNOS expression may be induced either by a direct effect of hypoxia on the endothelium or indirectly via enhanced carotid artery blood flow. Because the redistribution of fetal cardiac output occurs away from the periphery during fetal hypoxemia $(8,34)$, we speculate that the decrease in femoral artery blood flow leads to reduced shear stress, which in turn may result in a decrease in arterial eNOS expression (35).

It has been demonstrated that endothelium-derived NO in the fetal circulation is a potent vasodilator responsible for modulating fetal vascular reactivity $(36,37)$ and organ blood flow $(38,39)$. Chronic hypoxia may induce sustained release of endothelium-derived NO, thereby causing long-term changes in responsiveness to the underlying vascular smooth muscle. In our study, we speculate that chronic intermittent maternal hypoxia may induce intermittent release of endothelium-derived NO and redistribution of cardiac output. Our data suggest that chronic maternal hypoxia significantly increased eNOS expression in carotid arteries; thus, endothelium-derived NO may increase, contributing to decreased carotid artery tone and increased central blood flow. In addition, maternal hypoxia significantly decreased eNOS expression in femoral arteries; thus, endothelium-derived NO may decrease, contributing to increased femoral artery tone, decreased peripheral blood flow, and conservation of brain and heart perfusion.

In summary, previous studies have demonstrated an important role of eNOS in vascular function. The current study demonstrates that chronic intermittent maternal hypoxia alters eNOS gene expression in the carotid artery endothelium differently than in the femoral artery endothelium. The functional roles of differential eNOS expression in response to chronic hypoxia in vivo are not currently clear, but it may be an important adaptive response during hypoxia in modulating arterial reactivity.

\section{METHODS}

\section{Animal Model}

All experimental procedures were in accordance with National Institutes of Health guidelines with approval by the Standing Committee on Ethics and Animal Experimentation at the Fujian Medical University (China). Pregnant New Zealand White rabbits (Shanghai Experimental Animal Center, Shanghai, China) were time mated (term $=30 \pm 1 \mathrm{~d}$ ). On day 10 , rabbits were randomized to normoxic control and maternal hypoxia groups. Throughout pregnancy, rabbits were housed individually in standard rabbit cages, which were maintained in a clean conventional facility, with $55 \%$ humidity and a room temperature of $23{ }^{\circ} \mathrm{C}$, natural light, and ad libitum access to food (standard lab rabbit chow) and water.

\section{Intermittent Maternal Hypoxia}

According to the procedure of Wang et al. (40), from day 10 to day 29 of pregnancy, five pregnant rabbits were placed inside a plexiglass chamber twice per day, $4 \mathrm{~h}$ in the morning and $4 \mathrm{~h}$ in the afternoon. The oxygen supply was then reduced to $12 \pm 0.5 \%$ oxygen by continuous infusion of a nitrogen gas and compressed air mixture. The expired carbon dioxide was eliminated by circulating the atmosphere through soda lime, and the water contained in the expired gas was trapped in a chilled glass tank. A portable oxygen analyzer (IST-AIM, Chicago, IL) was calibrated daily and used to monitor the oxygen concentration of the chamber. Normoxic controls $(n=5)$ were put into an identical plexiglass chamber, into which compressed air was continuously infused. They then underwent the same procedures as the animals exposed to hypoxia.

\section{Tissue and Blood Collection}

At near term (29 d of gestation), pregnant mothers were anesthetized with i.v. sodium amobarbital $(30 \mathrm{mg} / \mathrm{kg}$; Amresco, Solon, OH), and control and maternal hypoxia fetuses were removed from the abdomen via a hysterotomy. All the fetuses were weighed. Blood samples were collected into tubes treated with EDTA dipotassium salt dihydrate from the aorta of anesthetized adults and via cardiac puncture from two fetuses per litter from control and maternal hypoxia litters. Aliquots of blood were analyzed on a hematology analyzer (HV950FS; Drew Scientific, Waterbury, CT). The remaining portion of the blood sample was centrifuged (Allegra X-22R; Beckman, Palo Alto, CA) at $1,000 \mathrm{~g}$ and $4^{\circ} \mathrm{C}$ for $30 \mathrm{~min}$, and aliquots of plasma were stored at $-70^{\circ} \mathrm{C}$ for measurement of EPO. Common carotid and femoral arteries, which were gently isolated from fetuses, were cleaned of adherent tissue and flash-frozen in liquid nitrogen and stored at $-70{ }^{\circ} \mathrm{C}$ for subsequent western blot determination of eNOS content, colorimetric determination of total NOS activities, and real-time reverse-transcriptase PCR analysis of eNOS mRNA abundance. For immunohistochemical staining of eNOS protein, the right common carotid arteries, which were isolated from one fetus per litter from control and maternal hypoxia litters, were cut into rings $1.5 \mathrm{~cm}$ in length and further fixed with $10 \%$ formalin overnight. Tissues were processed by standard procedures in graded alcohols and xylene, paraffin embedded, and stored at room temperature. Brain, heart, lung, liver, and kidneys were dissected from two fetuses per litter for the determination of relative weights.

\section{EPO Enzyme-Linked Immunosorbent Assay}

Plasma levels of EPO were analyzed using an ELISA Kit (ADL, Westchester, NY) per the manufacturer's instructions.

\section{Quantitative Western Blot Analysis of eNOS}

eNOS protein content was evaluated with standard western immunoblot. Because of the small size of the isolated carotid and femoral arteries, two left common carotid arteries and two left femoral arteries were obtained from two different fetuses from the same litter and pooled as a single sample, representing an $n$ value of 1 . Artery segments were homogenized using lysis buffer, homogenates were centrifuged at $12,500 \mathrm{~g}$ at $4{ }^{\circ} \mathrm{C}$ for $5 \mathrm{~min}$, and the soluble protein content of the supernatant was determined by a bicinchoninic acid protein assay kit (Beyotime Biotechnology, Shanghai, China). For western immunoblot, $30 \mu \mathrm{g}$ of total protein were loaded on gels and separated by electrophoresis and membrane transfer. The gels were probed by a specific eNOS antibody (anti-eNOS, 1:200 dilution; Boster, Wuhan, China). As a loading control, $\beta$-actin was also detected with anti- $\beta$-actin antibody (1:1,000 dilution; Beyotime Biotechnology). Proteins were visualized using enhanced chemiluminescence reagents (Beyotime Biotechnology). The intensity of bands was analyzed with Quantity One v4.62 analyzer software (Bio-Rad, Hercules, CA). The results are expressed as a ratio of the density of the eNOS band to the $\beta$-actin band.

\section{Determination of Total NOS Activities by Colorimetric Method}

Arterial total NOS activities were determined using the NOS assay kit (A014; Jiancheng Bioengineering, Nanjing, China) and the manufacturer's protocol. The activity of total NOS was assayed by nitrites and nitrates produced from L-arginine. In brief, the supernatants of 
the artery tissue homogenates $(100 \mu \mathrm{l})$ were incubated in $50 \mathrm{mmol} / \mathrm{l}$ Tris-HCl buffer ( $\mathrm{pH} 7.5$ ) containing the cofactors and the substrate $\mathrm{L}^{-}$ arginine, for $15 \mathrm{~min}$ at $37^{\circ} \mathrm{C}$. After the incubation period, the reaction was quenched by the addition of $1 \mathrm{ml}$ of stop buffer. The concentration of the nitrites and nitrates in the reaction mixture was determined by a colorimetric method (530-nm absorbance) to evaluate the NOS activity. All samples were assayed in triplicate and averaged.

\section{Quantification of eNOS mRNA by Real-Time Reverse- Transcriptase PCR}

Total RNA was extracted from the right common carotid arteries and right femoral arteries by TRIzol (Invitrogen, Carlsbad, CA) according to the manufacturer's instructions. RNA concentrations were determined by spectrophotometry at $260 \mathrm{~nm}$ (ND-1000; Thermo, Wilmington, DE). cDNA was synthesized using SuperScript II (Invitrogen) and random hexonucleotide primers. eNOS sequences were obtained from National Center for Biotechnology Information/ GenBank databases. Primer 3 software (http://frodo.wi.mit.edu/ primer3/) was used to design the primers. The following sequences were used as primers for eNOS and $\beta$-actin: $5^{\prime}$-CAA GAC CTA CGT GCA GGA CAT C-3' (forward) and $5^{\prime}$-AAG GAG AAA CTC TGG GTG CGT A-3' (reverse), and 5'-ATC AAG GAG AAG CTG TGC TAC G-3' (forward) and 5'-AGG AAG GAG GGC TGG AAG AG-3' (reverse), respectively. Real-time PCR was performed with an iCycler using SYBR Premix Ex Taq (TaKaRa Biotechnology, Dalian, China). The two-step quantification cycling protocol was used. eNOS mRNA expression was normalized to that of the housekeeping gene $\beta$-actin mRNA and quantified by the $2-\Delta \Delta C_{\mathrm{t}}$ method (41).

\section{Immunohistochemistry for eNOS}

Three consecutive 5 - $\mu \mathrm{m}$ sections from each specimen were deparaffinized in a standard series of xylenes and graded alcohols. Antigen retrieval was performed in $0.01 \mathrm{~mol} / \mathrm{l}$ citrate buffer $(\mathrm{pH}$ 6.0). Slides were placed in a beaker of citrate buffer, and this beaker was placed in a separate, larger beaker of boiling water. Slides were kept in citrate buffer in boiling water for $10 \mathrm{~min}$ and then cooled in buffer to room temperature. Subsequently, we used the Ultrasensitive Streptavidin-Peroxidase Kit (KIT-9706; Maixin-Bio, Fuzhou, China), and immunohistochemical analysis was performed by the streptavidin-peroxidase method. The primary antibody used was a rabbit polyclonal antibody against eNOS (1:100 dilution; Boster). Negative-control sections were incubated in blocking buffer alone without primary antibody. Each section underwent 3,3'-diaminobenzidene (DAB-0031; Maixin-Bio) staining and hematoxylin restaining. For each section of areas selected to include only the endothelium, five fields were randomly chosen, and the values of the average optical density were measured under the same magnification (original magnification $\times 600$ ) using a color image analysis system.

\section{Statistical Analyses}

Relative organ weights were measured as a ratio of the fetal organ weight normalized to the respective body weight. eNOS mRNA levels obtained were measured as $2-\Delta \Delta C_{t}$ values. Results were presented as grouped means \pm SD. The unpaired Student's two-tailed $t$-test was used for comparing two groups wherever appropriate, and two-way ANOVA was used for comparisons among more than two groups. Probability values of $<0.05$ were considered statistically significant. All data analyses were performed with Statistical Product and Service Solutions 11.5 (SSPS 11.5; SSPS, Chicago, IL).

\section{ACKNOWLEDGMENTS}

We acknowledge Jianhua Xu, Institute of Clinical Pharmacology, Fujian Medical University, for his assistance on this project.

\section{STATEMENT OF FINANCIAL SUPPORT}

This work was supported by grants from the Key Program of Scientific Research of FuJian Medical University, China (grant 09ZD015); Key Science and Technology Projects of Fujian Provincial Department of Education, China (grant JA11322); and Key Projects of Quanzhou Scientific Committee, China (grant 2009Z59).

\section{REFERENCES}

1. Zhang L. Prenatal hypoxia and cardiac programming. J Soc Gynecol Investig 2005;12:2-13.

2. Teramo KA. Obstetric problems in diabetic pregnancy - the role of fetal hypoxia. Best Pract Res Clin Endocrinol Metab 2010;24:663-71.

3. Patterson AJ, Zhang L. Hypoxia and fetal heart development. Curr Mol Med 2010;10:653-66.

4. Giussani DA, Riquelme RA, Moraga FA, et al. Chemoreflex and endocrine components of cardiovascular responses to acute hypoxemia in the llama fetus. Am J Physiol 1996;271(1 Pt 2):R73-83.

5. Thompson JA, Richardson BS, Gagnon R, Regnault TR. Chronic intrauterine hypoxia interferes with aortic development in the late gestation ovine fetus. J Physiol 2011;589:3319-32.

6. Moore LG. Fetal growth restriction and maternal oxygen transport during high altitude pregnancy. High Alt Med Biol 2003;4:141-56.

7. Calvert SA, Widness JA, Oh W, Stonestreet BS. The effects of acute uterine ischemia on fetal circulation. Pediatr Res 1990;27:552-6.

8. Morrison JL. Sheep models of intrauterine growth restriction: fetal adaptations and consequences. Clin Exp Pharmacol Physiol 2008;35:730-43.

9. Simonetta G, Rourke AK, Owens JA, Robinson JS, McMillen IC. Impact of placental restriction on the development of the sympathoadrenal system. Pediatr Res 1997;42:805-11.

10. Ruijtenbeek K, Kessels CG, Villamor E, Blanco CE, De Mey JG. Direct effects of acute hypoxia on the reactivity of peripheral arteries of the chicken embryo. Am J Physiol Regul Integr Comp Physiol 2002;283:R331-8.

11. Wilcox JN, Subramanian RR, Sundell CL, et al. Expression of multiple isoforms of nitric oxide synthase in normal and atherosclerotic vessels. Arterioscler Thromb Vasc Biol 1997;17:2479-88.

12. Phelan MW, Faller DV. Hypoxia decreases constitutive nitric oxide synthase transcript and protein in cultured endothelial cells. J Cell Physiol 1996;167:469-76.

13. Atochin DN, Huang PL. Endothelial nitric oxide synthase transgenic models of endothelial dysfunction. Pflugers Arch 2010;460:965-74.

14. Fiscus RR. Molecular mechanisms of endothelium-mediated vasodilation. Semin Thromb Hemost 1988;14:Suppl:12-22.

15. Williams JM, Hull AD, Pearce WJ. Maturational modulation of endothelium-dependent vasodilatation in ovine cerebral arteries. Am J Physiol Regul Integr Comp Physiol 2005;288:R149-57.

16. Thompson LP, Weiner CP. Effects of acute and chronic hypoxia on nitric oxide-mediated relaxation of fetal guinea pig arteries. Am J Obstet Gynecol 1999;181:105-11.

17. Thompson LP, Aguan K, Zhou H. Chronic hypoxia inhibits contraction of fetal arteries by increased endothelium-derived nitric oxide and prostaglandin synthesis. J Soc Gynecol Investig 2004;11:511-20.

18. Thompson LP, Dong Y. Chronic hypoxia decreases endothelial nitric oxide synthase protein expression in fetal guinea pig hearts. J Soc Gynecol Investig 2005;12:388-95.

19. Peyronnet J, Dalmaz Y, Ehrström M, et al. Long-lasting adverse effects of prenatal hypoxia on developing autonomic nervous system and cardiovascular parameters in rats. Pflugers Arch 2002;443:858-65.

20. Williams SJ, Campbell ME, McMillen IC, Davidge ST. Differential effects of maternal hypoxia or nutrient restriction on carotid and femoral vascular function in neonatal rats. Am J Physiol Regul Integr Comp Physiol 2005;288:R360-7.

21. Ostádalová I, Ostádal B, Jarkovská D, Kolár F. Ischemic preconditioning in chronically hypoxic neonatal rat heart. Pediatr Res 2002;52:561-7.

22. Nadaud S, Bonnardeaux A, Lathrop M, Soubrier F. Gene structure, polymorphism and mapping of the human endothelial nitric oxide synthase gene. Biochem Biophys Res Commun 1994;198:1027-33.

23. Shaul PW, Farrar MA, Zellers TM. Oxygen modulates endotheliumderived relaxing factor production in fetal pulmonary arteries. Am J Physiol 1992;262(2 Pt 2):H355-64.

24. Longo LD, Hull AD, Long DM, Pearce WJ. Cerebrovascular adaptations to high-altitude hypoxemia in fetal and adult sheep. Am J Physiol 1993;264(1 Pt 2):R65-72.

25. Ruijtenbeek K, Kessels LC, De Mey JG, Blanco CE. Chronic moderate hypoxia and protein malnutrition both induce growth retardation, but 


\section{Articles $\mid$ Chen et al.}

have distinct effects on arterial endothelium-dependent reactivity in the chicken embryo. Pediatr Res 2003;53:573-9.

26. Ruijtenbeek K, Kessels CG, Janssen BJ, et al. Chronic moderate hypoxia during in ovo development alters arterial reactivity in chickens. Pflugers Arch 2003;447:158-67.

27. Dong Y, Thompson LP. Differential expression of endothelial nitric oxide synthase in coronary and cardiac tissue in hypoxic fetal guinea pig hearts. J Soc Gynecol Investig 2006;13:483-90.

28. Arnet UA, McMillan A, Dinerman JL, Ballermann B, Lowenstein CJ. Regulation of endothelial nitric-oxide synthase during hypoxia. J Biol Chem 1996;271:15069-73.

29. Ostergaard L, Stankevicius E, Andersen MR, et al. Diminished NO release in chronic hypoxic human endothelial cells. Am J Physiol Heart Circ Physiol 2007;293:H2894-903.

30. Nishida K, Harrison DG, Navas JP, et al. Molecular cloning and characterization of the constitutive bovine aortic endothelial cell nitric oxide synthase. J Clin Invest 1992;90:2092-6.

31. Sessa WC, Pritchard K, Seyedi N, Wang J, Hintze TH. Chronic exercise in dogs increases coronary vascular nitric oxide production and endothelial cell nitric oxide synthase gene expression. Circ Res 1994;74:349-53.

32. Xiao Z, Zhang Z, Ranjan V, Diamond SL. Shear stress induction of the endothelial nitric oxide synthase gene is calcium-dependent but not calcium-activated. J Cell Physiol 1997;171:205-11.
33. Tuttle JL, Nachreiner RD, Bhuller AS, et al. Shear level influences resistance artery remodeling: wall dimensions, cell density, and eNOS expression. Am J Physiol Heart Circ Physiol 2001;281:H1380-9.

34. Boo YC, Jo H. Flow-dependent regulation of endothelial nitric oxide synthase: role of protein kinases. Am J Physiol, Cell Physiol 2003;285:C499-508.

35. Mulder AL, van Golde JC, Prinzen FW, Blanco CE. Cardiac output distribution in response to hypoxia in the chick embryo in the second half of the incubation time. J Physiol (Lond) 1998;508(Pt 1):281-7.

36. Garcia FC, Stiffel VM, Pearce WJ, Zhang L, Gilbert RD. Ca(2+) sensitivity of fetal coronary arteries exposed to long-term, high-altitude hypoxia. J Soc Gynecol Investig 2000;7:161-6.

37. GarciaFC,StiffelVM, GilbertRD.Effects oflong-termhigh-altitudehypoxia on isolated fetal ovine coronary arteries. J Soc Gynecol Investig 2000;7:211-7.

38. Jensen A, Garnier Y, Berger R. Dynamics of fetal circulatory responses to hypoxia and asphyxia. Eur J Obstet Gynecol Reprod Biol 1999;84:155-72.

39. Thornburg KL, Reller MD. Coronary flow regulation in the fetal sheep. Am J Physiol 1999;277(5 Pt 2):R1249-60.

40. Wang Z, Huang Z, Lu G, Lin L, Ferrari M. Hypoxia during pregnancy in rats leads to early morphological changes of atherosclerosis in adult offspring. Am J Physiol Heart Circ Physiol 2009;296:H1321-8.

41. Livak KJ, Schmittgen TD. Analysis of relative gene expression data using real-time quantitative PCR and the 2(-Delta Delta C(T)) Method. Methods 2001;25:402-8. 